Rodrigues, J. M. Ecoturismo construindo a materialidade dos assentamentos: uma história de legitimação da terra no Distrito Federal - DF. Revista Brasileira de Ecoturismo, São Paulo, v.2, n.2, 2009, pp.118-141.

\title{
Ecoturismo construindo a materialidade dos assentamentos: uma história de legitimação da terra no Distrito Federal-DF
}

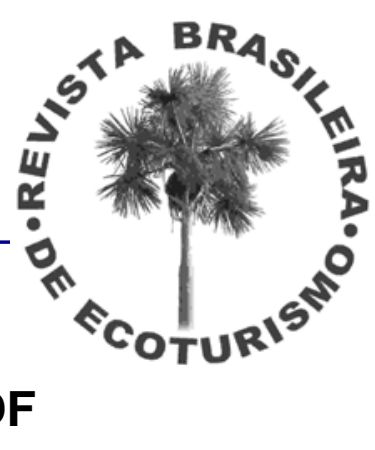

\section{Juarez Martins Rodrigues}

\begin{abstract}
RESUMO
Este estudo faz um levantamento e análise de processos participativos, analisando como os mesmos contribuem para instrumentalizar a implementação de políticas e o incremento de projetos sustentáveis, junto aos trabalhadores rurais do Projeto de Assentamento - PA Colônia I, no Município de Padre Bernardo Goiás, assentados pelo Programa Nacional de Reforma Agrária-PNRA, no ano de 1996. A metodologia utilizada na pesquisa buscou revelar a percepção da comunidade quanto à implementação das atividades ecoturísticas. Por meio de perguntas sobre Ecoturismo, investigou-se as concepções quanto aos aspectos relacionados às potencialidades, cuidados, produtos ofertados, educação, parcerias, as expectativas da comunidade em relação a geração de benefícios socioambientais, e a elaboração de estratégias factíveis na concepção, planejamento e desenvolvimento de um projeto turístico sustentável. Constatou-se que $44 \%$ dos mesmos pertencem ao Grupo Vida e Preservação do Colônia I, bem como a existência de outros processos organizativos, como do grupo de mulheres (em torno de 11) que desenvolvem a produção de artesanatos e se organizam para a produção de alimentos. Há interesse e disposição das comunidades de levar em frente a idéia de diversificação das atividades, aliadas ao manejo adequado dos recursos naturais e exploração em parceria com Projeto de Assentamento Colônia II, para viabilizar o Ecoturismo baseado na oferta de produtos alimentares, artesanatos, preparação interna e da população do entorno, desenvolver a proteção e infra-estrutura básica junto a alguns atrativos levantados, a geração de serviços e benefícios internos. Na concepção dos entrevistados a atividade poderá contribuir para o fortalecimento de sua representatividade política junto às instituições governamentais e junto à sociedade.
\end{abstract}

PALAVRAS-CHAVE: Ecoturismo, Participação Comunitária, Assentamento

\section{Ecotourism: building materiality in rural settlements and legitimating land ownership in the Federal District (DF), Brazil}

\section{ABSTRACT}

This study raises data on and analyzes participatory processes, examining how such processes contribute to the instrumentalization and policy implementation as well as increased interest in sustainable projects with rural workers of Settlement Project PA Colony I (Padre Bernardo municipality in the State of Goiás), who were settled by the Brazilian National Program for Agrarian Reform in 1996. The used research methods sought to reveal the community's perception about the implementation of eco-tourism activities. Through questioning on eco-tourism, we investigated conceptions regarding aspects pertaining to potentialities, care, offered products, education, partnerships, community expectations on socio-environmental benefits, and the set up of concrete strategies for conception, planning, and development of a sustainable eco-tourism project. We observed that $44 \%$ of workers belong to the group "Life and Preservation of Colony I" (Vida e Preservação da Colônia I), and other organizational processes such as women's group (around 11 individuals) who produce handcrafts and get organized for food production. There is interest and community's willingness to carry on a diversifycation of activities coupled with proper natural resources exploitation and management in partnership with the Project Settlement Colony I, in order to make eco-tourism feasible through such products as food, handcrafts, capacity building of local and surrounding population, development of protection and basic infrastructure with some attractions identified during the study, as well as generation of other services and goods. According to participants, such activities will contribute to the reinforcement of their politic representativeness before governmental institutions and the society as a whole.

KEY-WORDS: Ecotourism, Community Participation, Rural Settlement 


\section{Introdução}

Pecar por silêncio, quando se deveria protestar, transforma homens em covardes.

A. Lincoln

A história da formação do espaço agrário brasileiro, desde o colonial-escravista até $o$ atual momento, nos demonstra que as forças gerenciadoras do território atuaram no sentido de regular juridicamente a propriedade fundiária em função da posse por determinados grupos: ora para a classe senhorial plantacionista, ora para os senhores feudais, ora para uma burguesia agrária com vistas a produção em grande escala para o mercado internacional (MOREIRA, 1981).

Historicamente, tem-se uma série de exemplos de resistência e rompimento desse processo, conduzidos pelos movimentos sociais.

As lutas camponesas sempre tiveram presentes na história do Brasil. Os conflitos sociais no campo não se restringem ao nosso tempo. Alguns exemplos foram a Guerra dos Potiguaras, Confederação dos Tamoios, Palmares, Canudos entre outros (FERNANDES, 2000:25-47).

Em relação à mobilização social no campo, houve o movimento iniciado no final dos anos 1950, liderado por Francisco Julião desencadeado em Pernambuco e espaIhado por todo o Nordeste, conhecido como Ligas Camponesas, e, no início dos anos 1960, o Movimento dos Agricultores Sem Terra - MASTER, ocorrido no Rio Grande do Sul. "Esses dois movimentos seriam os precursores do Movimento dos Trabalhadores Sem Terra - MST" (VASCONCELOS, 2002:27).

A acumulação capitalista historicamente beneficiada pelas leis e programas governamentais, configurando-se numa classe dominante com base na propriedade da terra, intensificou a grande propriedade, mais uma vez beneficiada, pelas políticas públicas e por meio dos incentivos fiscais, período que se inicia na década de 1950, acentuando-se nas décadas de 1960 e 1970, com a chamada revolução verde.

Esse processo gerou a expulsão de milhares de trabalhadores e produtores familiares de suas terras, para dar lugar à agricultura e à pecuária, intensivas em capital e extensivas em área, acarretando sérios problemas sociais nos centros urbanos. O êxodo rural configura-se por uma acelerada redução da população rural do país. Nos anos 1960, 80\% da população brasileira viviam no campo e após três décadas percebe-se que esse percentual corresponde ao contingente de pessoas que habitavam nas cidades.

Ainda na década de 1960, como resultado das discussões desencadeadas referente ao êxodo rural e processos de desagregação social, como o desemprego dos trabalhadores rurais nas cidades, no Brasil e em outros países da América Latina, e para regulamentar as questões da terra no país, o governo criou o Estatuto da Terra em 1964, o Instituto Nacional de Colonização e Reforma Agrária (INCRA), e outros órgãos com o objetivo de promover a Reforma Agrária. 
No entanto, frente à ineficiência governamental, à pressão e ao crescimento dos latifúndios, onde a produção é cada vez mais caracterizada pela agricultura mecanizada e voltada para a exportação, agravando o desemprego no campo e na cidade, surge o Movimento dos Trabalhadores Sem Terra - MST, apoiado por outros segmentos da sociedade, para promover uma ruptura sobre o domínio da terra no país, e assegurar o direito a terra.

Ao longo desses anos, o MST configura-se como o principal movimento popular do país, com suas ações pela Reforma Agrária e fixação no campo, de milhares de trabalhadores. Neste início de século XXI, vem suscitando uma contra-reação da classe dominante, em grande parte induzida pelas visões tendenciosas dos meios de comunicação em massa, e fortalecida pela ideologia dos latifundiários, principais interessados na manutenção de seus privilégios político-sócio-econômicos.

No Estado de Goiás, foi na década de 1980 que surgiram as primeiras ocupações de terra (MORAES, 1999), e delas surgem os primeiros assentamentos rurais.

Essas ocupações não aconteceram de forma planejada, e se iniciam numa espécie de evolução que passou da pura resistência isolada, em posses antigas, à ocupação devidamente planejada de área previamente escolhidas, sob a orientação de sindicatos, Diocese de Goiás e MST.

Referente ao tema agrário, Oliveira (1999:17) diz que

a particularidade do MST se deve pela recusa à migração, substituída pela luta para ficar, para se encontrar, encontrar com a terra prometida, encontrar com a identidade negada de Sem Terra e por esta negação, se afirmarem como cidadãos em luta contra a concentração de terras, contra o Estado brasileiro, contra o capital mundializado.

Portanto, a atual discussão sobre "modelos e processos" que vem substituir o desenvolvimento segmentado e ambientalmente desagregador de recursos naturais, tem sua matriz numa visão mais holística de vida e de sociedade, perpassando pelo desenvolvimento com equidade social ou desenvolvimento socioambiental.

A partir do acúmulo das organizações de trabalhadores rurais assentados, e as estratégias de planejamento e desenvolvimento das potencialidades da região do entorno do Distrito Federal, baseados na reflexão histórica das premissas referente à adoção de modelos socioambientais de desenvolvimento, realizou-se esta pesquisa em dois assentamentos rurais: Colônia I e Colônia II, situados no Estado de Goiás, na região do Entorno do DF.

Nesse contexto o enfoque para o Ecoturismo se dá por um lado pela capacidade de organização e articulação entre os moradores dessa localidade e entorno, sobretudo com o plano piloto de Brasília, Universidade de Brasília-UnB, Ministério do Desenvolvimento Agrário-MDA, há portanto nessa localidade uma materialização de esforços voltados para a integração de políticas públicas, e se somadas a outras potencialidades naturais no sentido de a compatibilizar as ações governamentais que busquem a proteção desses recursos associados a participação dos atores locais no desenvolvimento das atividades turísticas. 
A conformidade destas ações e políticas já em andamento são perfeitamente compatíveis com as premissas do Ecoturismo, e para os Ministérios do Comércio da Indústria e Turismo e do Meio Ambiente-MICT/MMA, conforme as Diretrizes para uma Política Nacional de Ecoturismo ele é

um segmento da atividade turística que utiliza, de forma sustentável, o patrimônio natural e cultural, incentiva sua conservação e busca a formação de uma consciência ambientalista através da interpretação do ambiente promovendo 0 bem estar das populações envolvidas (EMBRATUR, 1994).

Outros fatores contribuem para o interesse da pesquisa e reflexão quanto à implementação do Ecoturismo nos assentamentos, que somados às articulações interinstitucionais e organizações coletivas entre os moradores do Projeto de Assentamento - PA Colônia I, dizem respeito à diversificação das atividades socioeconômicas a exemplo do grupo de mulheres (em torno de 11) que desenvolvem a produção de artesanatos e se organizam para a produção de alimentos.

Há interesse e disposição das comunidades de levar em frente proposta de um turismo sustentável, a partir do manejo adequado dos recursos naturais e exploração em parceria com Projeto de Assentamento Colônia II, para viabilizar o Ecoturismo baseado na oferta de produtos alimentares, artesanatos, preparação interna e da população do entorno, desenvolver a proteção e infra-estrutura básica junto a alguns atrativos levantados, a geração de serviços e benefícios internos. Na concepção dos entrevistados a atividade poderá contribuir para o fortalecimento de sua representatividade e melhoria das condições de vida dos assentados.

Aliado a estes fatores é a experiência histórica de luta de seus habitantes pela terra, e a incorporação de processos coletivos de produção sustentada, assim como a demonstração de interesse de seus moradores de realizar parceria com habitantes de do Assentamento PA Colônia II, sendo que os moradores de ambos vivenciaram os mesmos processos de resistência e ocupação da terra, pois antes pertenciam a um mesmo acampamento.

São também fatores importantes para a realização da pesquisa os seguintes aspectos favoráveis ao desenvolvimento de atividades de caráter participativo e comunitário:

- Atrativos naturais como cachoeiras, bosques naturais, capacidade de articulação, produção orgânica, artesanatos, comida típica e serviços.

- Existência no local de processos organizativos e de mobilização junto aos assentados;

- Experiência de articulação e o apoio de instituições de pesquisa e educação como a Universidade de Brasília (UnB), INCRA-PRONERA, e Escola Agrotécnica Estadual de Unaí-MG, no desenvolvimento de projeto voltado para a capacitação de alunos e monitores do assentamento Colônia I; 
Rodrigues, J.M.

- Articulação e apoio de instituições de pesquisa e de assistência técnica, como a Empresa Brasileira de Pesquisa Agropecuária EMBRAPA- Cerrados e Empresa de assistência técnica e extensão rural - Emater;

- Implementação de atividades por meio de linhas de créditos e Programas de capacitação do Ministério do Trabalho;

- Estabelecimento de parcerias com instituições que atuam com a implementação de programas voltado para a conservação, recuperação e proteção dos recursos naturais, como o Ministério Público do Distrito Federal e Territórios;

- Desenvolvimento de atividades produtivas de caráter coletivo, como a horta orgânica, viveiro florestal e centro comunitário;

- Criação do grupo Vida e Preservação voltado para a produção sustentável;

- Relação com o público consumidor, por meio da realização de feiras livres de produtos alimentícios;

- Recepção de grupos de visitantes no local do assentamento;

- Proximidades com o centro comercial de Brasília;

- Mudanças de hábitos e comportamentos demonstrados pela comunidade.

Esses fatores e as ações pró-ativas para ampliar as parcerias junto aos órgãos governamentais nas esferas municipal, distrital e federal, e junto a outras instituições de apoio, que poderão potencializar suas iniciativas, constituem-se em "ferramentas" valiosas para viabilizar seus planos e dar concretude aos seus projetos, podendo até influenciar e estimular a adoção de políticas públicas e estratégias de desenvolvimento socioambiental nos níveis local e regional.

Com base em todos os aspectos acima mencionados espera-se que a pesquisa contribua para o planejamento e a implementação de estratégias conjuntas voltadas ao desenvolvimento de atividades ecoturísticas nessas comunidades.

\section{O Assentamento Colônia I}

O sonho que a gente sempre gosta de realizar é um sonho assim, que eu tenho em mente desde quando a gente entrou aqui: é o Ecoturismo. Eu queria que isso melhorasse, a gente gostaria de mostrar, ter oportunidade de sentar e contar a nossa história... Mostrar a cerca da preservação da natureza e tudo... (Valdemir S. Veloso, reside no Assentamento Colônia I).

\section{História e experiências vividas}

O Projeto de Assentamento PA Colônia I está inserido na Área de Proteção Ambiental do Lago do Descoberto, e se encontra no quadrante geográfico 15036'59" por

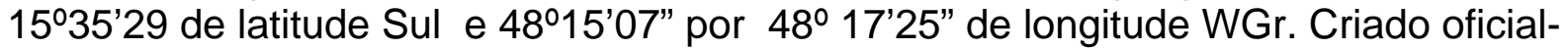
mente em 1996, está localizado no Município de Padre Bernardo-GO, nas proximidades do povoado de Monte Alto, a $15 \mathrm{KM}$ de Brazlândia- DF, a $80 \mathrm{KM}$ de Brasília, inse- 
rido na área de Proteção Ambiental- APA do Descoberto.

Possui características e problemas estruturais semelhantes aos dos demais assentamentos da região e do país, como as deficiências das ações voltadas para os setores básicos, como saúde, educação, transporte, abastecimento d'água e fragilidade dos programas de apoio à produção rural.

No entanto, a localidade apresenta as potencialidades já identificadas no município, com algumas peculiaridades, como a facilidade de acesso, a beleza cênica dos recursos naturais existentes dentro da área dos assentados, com inúmeras cachoeiras, escarpas dos morros, mirantes, trilhas, nascentes, mata ciliar e a biodiversidade do cerrado. Outros pontos positivos, como a diversidade de produtos turísticos, a produção orgânica, o artesanato e a alimentação natural, são também relevantes no processo e devem ser agregados aos atrativos anteriormente mencionados.

O assentamento das famílias nessa localidade é conseqüência da trajetória de vários trabalhadores que, desde 1994, se mobilizam, se deslocam e resistem nos acampamentos. Primeiramente as 100 famílias que integravam esse movimento, acamparam na Fazenda Imperial, de onde foram despejados. Em seguida se estabeleceram na localidade conhecida com Chapadinha, no Município de Brazlândia.

O Assentamento Colônia I é hoje formado por 24 famílias, as áreas dos lotes variam de 16,5 a 24 hectares, sendo de 560,5 hectares, a área total do assentamento. Desse total 3,4 hectares foram destinados para uso coletivo e 159 hectares correspondem à área de preservação permanente. Para cada lote foi destinada a área de reserva legal.

Em 1996 é criada a Associação dos Produtores do Projeto Colônia I (APPC), com objetivo de realizar a organização social, a captação, distribuição e o controle do crédito rural da época - O Programa de Crédito Especial para a Reforma Agrária (PROCERA), prestar assistência, defender e representar legalmente a comunidade junto aos órgãos competentes.

As práticas produtivas adotadas no Colônia I, na sua primeira experiência de aplicação de recursos financeiros do PROCERA, não fora diferentes do que normalmente se adota país afora: padronização das culturas a serem implantadas, a convencionalidade dos conhecimentos e da assistência técnica, uniformização do solo, e desconsideração das relações familiares e de trabalho.

Mediante orientação da assistência técnica, todos os parceiros adotaram um mesmo módulo de produção de cana-de-açúcar, capim, mandioca e criação de gado de leite. Como o esperado, nem a produção nem o crédito viabilizaram melhorias para a comunidade; pelo contrário, gerou conflitos, dívidas e frustrações.

Em 2001 por meio do Programa Nacional de Geração de Renda - PRONAGER foram formados grupos para o trabalho coletivo, sendo tomadas algumas iniciativas de caráter organizativo e gerencial, formação de cooperativas, a partir da execução de projetos de suinocultura, piscicultura, criação de galhas, produção de defumados e plantio de maracujá. Nesse Programa foram ministrados cursos voltados para produção de composto, produção de mudas, administração e gerenciamento do viveiro florestal comunitário, curso de cooperativismo, curso de horta orgânica, elaboração de projeto, oficinas de artesanatos e produção de brinquedos com uso de lixo reciclado. 
Diversos fatores adversos, no entanto, produziram resultados pouco satisfatórios para esse programa.

\section{Caracterização socioambiental}

A região onde se localiza o Assentamento predomina o relevo acidentado, com a ocorrência de escarpas de morros e montanhas, de vegetação remanescente do cerrado, como também gramíneas e vegetação rupestre, que proporciona uma beleza cênica peculiar ao lugar. Esses lugares que apresentam maiores declividades, e são considerados ambientes de maior fragilidade e susceptibilidade a processos de degradação ambiental, foram destinados a Reserva legal do assentamento, correspondendo a 159 ha.

No entanto, face aos sistemas de produção agropecuária adotados no período anterior à desapropriação das terras destinadas ao assentamento, propiciou-se a perda de boa parte da vegetação nativa, a redução da biodiversidade, o desencadeamento de processos erosivos, a degradação das áreas que eram destinadas a pastagens, a retirada de madeira das matas ciliares com impactos negativos às nascentes e aos recursos hídricos.

Tais fatores devem-se a pouca vegetação protegendo o solo e a construção da estrada principal que liga o assentamento à cidade de Padre Bernardo. A falta de vegetação nativa na área vem provocando impactos diretamente relacionados aos recursos hídricos e ao abastecimento do lençol freático, uma vez que a ausência de cobertura vegetal e a compactação impede sua penetração no solo. Contribuindo para a formação de enxurradas responsáveis pelas erosões na localidade.

Outro fator negativo diz respeito à construção da estrada GO 425, que liga Brazlândia a Padre Bernardo, sem o devido planejamento, como a falta de instalação de obras de contenção, como as bacias e canais de escoamento e reflorestamento das áreas de empréstimos e margens da estrada, contribuindo para agravar os processos erosivos já mencionados acima.

Ainda referente à herança deixada pelo modelo de produção perverso aos recursos ambientais existentes no local, há manejo inadequado dos rebanhos, com criação extensiva de bovinos, causando a compactação e perda da fertilidade do solo, desmatamentos, o uso do fogo para a "renovação" de pastagens, e o comprometimento dos recursos hídricos. Não há rios ou córregos cortando o assentamento. A existência de algumas nascentes nas áreas de preservação permanente não assegura o abastecimento de água potável e o seu uso na produção, visto a sua localização predominante nas áreas de maior declividade em altitudes inferiores às áreas cultivadas.

Com vistas a resolver a situação de precariedade no abastecimento d'água para as famílias, e com o pouco apoio financeiro por meio do crédito de instalação, concedido pelo INCRA, muitos assentados construíram cisternas para assegurar o fornecimento d'água a suas casas e a irrigação dos plantios.

Por outro lado, nesse período constata-se uma frustração, à medida que alguns 
dos moradores vão vender sua mão de obra nas propriedades rurais vizinhas ou mesmo nas cidades do entorno, como conseqüência do insucesso das ações produtivas apoiadas pelas iniciativas governamentais, teoricamente voltadas para promover as mudanças e assegurar melhorias nos serviços básicos e de melhorias de vida dos assentados.

Visto as experiências adquiridas no desenvolvimento das atividades produtivas no ano de 2001, os associados e os diretores percebem a necessidade de implementar mudanças e inserir novos critérios em sua organização social, inicialmente voltado para fortalecer o cooperativismo, e buscar o fortalecimento institucional da Associação.

\section{Parcerias e os avanços no fortalecimento institucional}

A estratégia de fortalecimento da APPC está diretamente vinculada à visão de ampliar a representação política dos assentados junto aos órgãos gestores de políticas públicas e de programas governamentais. Nesse sentido, são buscadas novas parcerias, e o diálogo com outras instituições que tenham experiência na implementação de processos sócio-educativos-ambientais.

No período de 1999 a 2001, por meio de uma parceria entre o GTRA/UNB, Embrapa Cerrados, INCRA, e o Instituto Interamericano para a Cooperação na Agricultura (IICA) foi realizado sob a coordenação do GTRA e da Faculdade de Educação da UNB, o Curso de Extensão e Especialização em Educação do Campo e Desenvolvimento Sustentável dos Assentamentos de Reforma Agrária- EDUCAMP, sendo que o diálogo entre essas instituições e as famílias assentadas possibilitou a capacitação de dois moradores do assentamento Colônia I.

Como resultado da metodologia adotada no curso, que permitiu disseminar os conhecimentos e a aplicação prática dos conhecimentos teóricos adquiridos, promovendo a discussão e o levantamento sócio-ambiental do assentamento, foi possível visualizar saídas e a implementação de ações com vistas a incrementar a produção, a recuperação de áreas degradadas e a diversificação das atividades produtivas por meio de tecnologias e práticas conservacionistas.

Outros aspectos que configuram amadurecimento da comunidade estão diretamente relacionados às parcerias entre os assentados e instituições de apoio e capacitação de monitores, por meio do curso EDUCAMP, e à ampliação do diálogo junto a outras instituições, com vistas a promover e desencadear processos nas áreas de formação e produção sustentada.

Nessa dimensão onde a participação dos atores locais acontece sob a ótica da interdisciplinaridade das ações desenvolvidas, a Educação Ambiental permeia os projetos em desenvolvimento nessa localidade, o que demonstra ser uma ferramenta de extrema importância na implementação de processos do desenvolvimento socioambiental na região. 
A Educação Ambiental é um campo aberto ao trabalho interdisciplinar necessário à construção do conhecimento coletivo, que consegue integrar atores sociais, natureza e cultura, instrumentalizando a ação transformadora (MARTINS; MELLO,_1993).

Nesse sentido, a Educação Ambiental possibilita a mudança de comportamento dos envolvidos no processo, onde poderá ser valorizada a conservação dos recursos naturais existentes nas suas localidades, aperfeiçoando os mecanismos de parcerias locais, a participação comunitária, o gerenciamento de empreendimentos, o controle, a regulamentação e a gestão dos recursos naturais de "uso comum", numa perspectiva do compromisso permanente desse atores em torno de um projeto turístico sustentável e de longo prazo.

Nesse processo é visível o fortalecimento da organização dos assentados. Por exemplo, após o curso anteriormente mencionado, os dois alunos do assentamento do Colônia I foram eleitos para ocupar cargos da diretoria da APPC.

Nesse sentido cresce a mobilização entre os associados da APPC, com o intuito de promover a reformulação do estatuto dessa organização, com vistas a ampliar seu espectro de atuação. É visível a ampliação do espectro sócio-políticoeconômico de atuação das famílias assentadas na reformulação do estatuto. Dentre eles, os mecanismos criados para garantir uma maior participação dos moradores, fortalecimento interno, trocas de experiências, parcerias e diversificação de atividades concebidas na ótica da sustentabilidade.

A partir da inclusão da previsão de compromissos dos assentados do Colônia I, na adoção de medidas voltadas para a recuperação de áreas degradadas e a proteção dos recursos hídricos na APA do Descoberto, tem se estabelecido o diálogo entre a Associação e a Promotoria de Meio Ambiente do Ministério Público do Distrito Federal e Territórios para implementar parcerias no âmbito do Programa de Medidas Alternativas aplicado aos infratores dos crimes ambientais praticados no DF.

Em meados de 2002, a APPC capta recursos para o projeto Educando para a Sustentabilidade: Hortas Orgânicas e Viveiro Florestal Comunitário como instrumentos de recuperação e preservação ambiental, de organização social e geração de renda para as famílias do assentamento. Doze famílias das vinte quatro famílias do assentamento, em fevereiro de 2003, fundaram com esses recursos o Grupo Vida e Preservação, que possibilitou o desenvolvimento de experiências na implementação de processos coletivos, que buscaram a sustentabilidade, como a adoção de práticas voltadas para o alcance de avanços e melhorias sócio-ambientais no assentamento.

O desenvolvimento desse projeto coletivo e a sua gestão por meio de premissas sustentáveis têm contribuído para fortalecer o cooperativismo, a solidariedade entre os moradores, apontando uma perspectiva de futuro, focada no âmbito do desenvolvimento local sustentável, a ser implementado mediante processos que se configuram em mudanças intrínsecas às comunidades, assim como busca a geração de benefícios locais e coletivos. 


\section{Metodologia}

A escolha dos temas e indagações realizadas nas entrevistas com os moradores dos dois assentamentos surgiu do diálogo com alguns moradores desses assentamentos, que demonstraram o interesse de implementarem parcerias com vistas a viabilizar atividades conjuntas de Ecoturismo e potencializar as ações afins. No assentamento Colônia I, eventualmente já há as famílias que recebem para visitação de grupos de estudantes da Universidade de Brasília, interessados em conhecer a produção da comunitária da horta e do viveiro florestal, a adoção de práticas sustentáveis, como a produção de, biofertilizantes, a produção do composto orgânico, o reflorestamento de áreas degradadas por meio do plantio de espécies nativas consorciado com leguminosas, e a produção do adubo natural a partir do aproveitamento de dejetos animais e vegetais- o composto orgânico.

Numa primeira etapa da pesquisa, foi feito a análise dos projetos e relatórios produzidos pela equipe que compõem o GTRA/UNB que atua junto às famílias do assentamento Colônia I. Esses documentos foram importantes para a compreensão do estudo e contribuíram para nortear os temas abordados na pesquisa de campo.

Com apoio do presidente da APPC, foram realizadas algumas visitas técnicas aos assentamentos e a partir de então se estabeleceu o diálogo com a comunidade dos assentamentos Colônia I e Colônia II, onde foi demonstrado o interesse e abertura para a discussão e reflexão referente às possibilidades de incrementar os processos produtivos e desenvolver atividades ecoturísticas, visto as especificidades e potencialidade existentes nessas localidades. Alguns depoimentos referentes às ações e projetos em desenvolvimento e a expectativa de incrementar os processos sustentáveis, reforçaram o interesse pela realização dessa pesquisa.

Procedeu-se a investigação por meio de questionário semi-estruturado a contendo perguntas com vistas a levantar a percepção dos moradores sobre as atividades ecoturísticas, e identificar alguns aspectos referentes aos benefícios sócio-ambientais, participação da comunidade, fortalecimento do processo organizacional, fragilidades, preocupações com a implementação do Ecoturismo e a continuidade do diálogo das comunidades entre si e com técnicos e instituições parceiras.

Os temas e questões abordadas no questionário foram estruturados em perguntas diretas, opcional e indagações com alternativas de respostas, divididas em três blocos:

A) Dados do Entrevistado: relacionado aos aspectos voltados para o reconhecimento e situação pessoal dos moradores, sendo as abordagens referentes à participação dos assentados, nos processos de que deram origem aos assentamentos, escolaridade, atividades trabalhadas e inserção sócio-ambiental;

B) O Turismo e o Ecoturismo: relacionado à percepção e ao entendimento pessoal dos entrevistados referente a esses temas; 
C) Perguntas para coleta de dados e informações que poderão possibilitar o incremento dos projetos produtivos, dos trabalhos já desenvolvidos pelos assentados na recepção e condução de grupos de alunos visitantes, bem como potencializar as práticas sustentáveis desenvolvidas, sobretudo subsidiar o planejamento sistêmico das atividades realizadas pelas famílias assentadas, assim como contribuir para a incorporação das atividades ecoturísticas, com vistas a ampliar a diversidade das atividades na perspectiva do crescimento socioambiental, e inseridas numa visão estratégica de desenvolvimento local sustentável.

O questionário foi aplicado para 11 pessoas, sendo 6 entrevistados do Assentamento Colônia I e 5 do PA Colônia II. Visto a significativa inserção dos homens e muIheres que atuam nos trabalhos desenvolvidos, as perguntas não se limitaram apenas aqueles que trabalham nos projetos coletivos, ainda que 5 dos entrevistados do assentamento Colônia I fizessem parte do Grupo e Vida e Preservação, formado por 12 famílias que desenvolvem o projeto Educando para a Sustentabildade: Hortas Orgânicas e Viveiro Florestal Comunitário. Todos os entrevistados participam da Associação dos Produtores do Projeto Colônia I - APPC.

Quanto aos 5 assentados do PA Colônia II, 3 são produtores orgânicos, os outros 2 depoimentos são de moradores que desenvolvem atividades produtivas convencionais, sendo que um tem suas atividades voltadas para o cultivo de frutíferas, horta e a criação de animais e outro entrevistado tem suas atividades voltadas para a criação de animais de pequeno porte. Todos são sócios da Associação dos Trabalhadores Rurais do Projeto de Assentamento Colônia II.

Nos dois assentamentos não houve um planejamento prévio para a aplicação do questionário, sendo o mesmo aplicado conforme as indicações dos próprios moradores, o interesse e a disponibilidade de tempo dos assentados para o diálogo, no momento das visitas aos assentamentos.

O tempo de duração da aplicação dos questionários durou em média 50 minutos, e buscou-se agregar informações pertinentes aos temas abordados nas entrevistas, considerando as observações dos assentados quanto aos problemas referentes a infra-estrutura, como a necessidade de buscar soluções para o abastecimento de água potável, e a preocupação levantada por alguns assentados, no sentido de ampliar a conscientização e o desenvolvimento do trabalho de Educação Ambiental junto a produtores hortifrutigranjeiros que são abastecidos a montante, pelo mesmo córrego que forma as cachoeiras do Colônia II, bem como foi abordado a necessidade de estendelo ao povoado de Monte Alto e à comunidade de Padre Bernardo.

\section{Discussão dos resultados}

As respostas às indagações que serão mencionadas abaixo, correspondem ao universo de entrevistados (11), independente do local onde reside o entrevistado. Como forma de contribuir para o enriquecimento da discussão dos resultados da pesqui- 
sa, serão consideradas as outras opções de respostas surgidas e argumentos referentes ao temas apresentados durante as entrevistas.

Como já mencionado o primeiro bloco de perguntas trata-se do levantamento de dados para conhecer a inserção de cada entrevistado no seu assentamento e perante a comunidade, como ele organiza sua produção, seu envolvimento na origem do processo de ocupação daquele espaço, e levantar aspectos referente a sua sustentabilidade e a perspectiva de futuro.

Os dados que serão mencionados a seguir se referem às respostas das indagações feitas no roteiro, nesse sentido se constitui numa primeira abordagem quantitativa, sem o aprofundamento qualitativo das respostas.

Em relação à origem dos assentados, dos 11 entrevistados, todos afirmaram ser procedentes do meio rural, sendo que 2 afirmaram ter passado por experiência de trabalho na cidade; um trabalhou no comércio e outro como marceneiro. Todos os entrevistados são moradores e desenvolvem atividades produtivas no respectivo assentamento. Apenas 1 tem a família morando na cidade de Brazlândia.

A faixa etária da maioria dos entrevistados varia de 31 a 40 e de 51 a 60, num total de 8. A maioria declarou que estudou até o $1^{\circ}$ grau incompleto, e apenas 1 dos entrevistados está cursando o curso técnico. No entanto demonstraram preocupações com a educação das crianças e dos jovens do assentamento, visto que os mesmos são obrigados a se deslocarem até as cidades vizinhas para estudar.

Com vistas a investir no desenvolvimento das praticas sustentáveis e na capacitação de monitores para atuação junto às famílias assentadas nos assentamentos Colônia I e II, por meio do diálogo entre os assentados e instituições parceiras, 2 jovens do Colônia I, e 1 do Colônia II estão fazendo o curso de Formação de Técnicos em Agropecuária de Desenvolvimento Sustentável para Assentamentos da Reforma Agrárias pelo sistema de alternância e integrado escola-aluno-comunidade, coordenado GTRA/UnB em parceria com a Escola Agrotécnica de Unaí e EMBRAPA, com recursos financeiros do Programa Nacional de Educação em assentamentos do Programa de Reforma Agrária - PRONERA.

Quanto às atividades econômicas desenvolvidas pelos assentados, 44\% dos entrevistados são membros do Grupo Vida e Preservação-Colônia I, e desenvolvem a produção orgânica e comunitária de hortaliças e mudas para reflorestamento de áreas degradadas, cerca de $36 \%$ desenvolvem a criação de animais (gado, galinha), sendo que $10 \%$ correspondem às três mulheres entrevistadas, sendo que dessas duas do PA Colônia I participam do grupo de mulheres, desenvolvendo atividades relacionadas a produção e fornecimento de alimentos orgânicos e naturais, a grupos de visitantes ao assentamento e para encontros/seminários externos. A construção do espaço comunitário apoiado pelo Projeto-Conservação e Manejo da Biodiversidade do Bioma Cerrado-CMBBC, incrementou as atividades desenvolvidas pelo grupo de mulheres.

A renda obtida pelas atividades econômicas varia de 1/2 a 01 salário mínimo, 1 entrevistado manifestou renda superior a 2 salários mínimos.

No segundo bloco as perguntas foram direcionadas a levantar a compreensão e o conhecimento empírico dos assentados referente ao turismo e ao Ecoturismo, com 
vistas a diagnosticar a concepção dos mesmos referentes às variáveis intrínsecas a essas atividades, se e quais estariam sendo mencionadas ou relacionadas com esses temas. Pretendia-se, também, diagnosticar se há uma percepção de diferenciação entre as práticas convencionais do turismo, e formas de condução e gestão dessa atividade. Outro item de interesse era o questionamento se havia uma compreensão dos entrevistados referente ao aspecto da relação da atividade ecoturística com a geração de benefícios para a comunidade.

Portanto, do total dos entrevistados, 10 assentados responderam afirmativamente que sabiam o que é turismo, e explicitaram suas compreensões sobre o tema de maneira clara e significativa. Em relação à pergunta se sabiam o que é Ecoturismo, mais de $70 \%$ dos entrevistados em resposta afirmativa associaram a atividade com a natureza, e cuidados com o meio ambiente e o restante dos entrevistados não conseguiu verbalizar idéias a respeito da pergunta, o que não significa que não tem ideias de como pode se desenvolver essa atividade.

Referente ao terceiro e último bloco, o foco das perguntas está diretamente relacionado com a comunidade, nos aspectos de mudanças e influências no comportamento dos moradores, geração de atividades novas, benefícios e problemas gerados, preparação da comunidade e cuidados a serem tomados, e aborda aspectos considerados importantes para a atividade, como o planejamento, organização, participação e integração entre os dois assentamentos, aborda questões relacionadas aos atrativos e potencialidades da localidade, parcerias e apoio na implementação das atividades ecoturísticas.

Um primeiro aspecto, que pode ser considerado relevante e contribuir na discussão dos resultados obtidos com a pesquisa, é referente à origem rural das famílias assentadas, assim como o fato dos residentes nos dois assentamentos terem originalmente pertencido a um mesmo grupo, que iniciou o processo de luta pela terra desde o ano de 1995. Esse componente histórico é um fator de agregação entre os assentados e potencializa os interesses comuns, no sentido da implementação de projetos e atividades econômicas sustentáveis, dentro dos princípios de inserção participativa das comunidades envolvidas.

Em relação às famílias assentadas, as entrevistas indicaram uma situação diferente quando se analisa o aspecto da posse da terra em cada um dos dois Projetos de Assentamento. No Colônia I, permanecem os mesmos proprietários dos lotes, enquanto no Colônia II, do total dos 24 famílias assentadas no início do Projeto, menos de $50 \%$ ainda mantêm a posse de suas áreas.

Além dos fatores externos, como a especulação imobiliária do entorno, a ineficácia das políticas públicas para os assentados, há que se considerar outros fatores que evidenciam a diferença dessas duas realidades. Um diz respeito ao fortalecimento do processo organizativo, que vem contribuindo significativamente para a consolidação das atividades econômicas das famílias do PA Colônia I, onde se percebe a inversão do êxodo rural, ou seja, o retorno de mão de obra para as atividades produtivas do assentamento. 
Nessa perspectiva a discussão referente ao incremento dos processos em curso e a existência de conflitos específicos em cada um dos assentamentos, deverá ir além dos "interesses comuns", mas sim pelo viés do estabelecimento de critérios participativos, onde os atores locais atuam como sujeitos legítimos, nas diferentes etapas da implementação de projetos coletivos, ou seja, na concepção, planejamento e execução dos mesmos.

Em relação às atividades econômicas, é bastante representativa a posição assumida pelos produtores orgânicos constatada nos dois assentamentos, que se configuram como catalisadores dos processos, sobretudo por meio das parcerias já implementada pelo Grupo Vida e Preservação que, desde a sua fundação em 2002, vem ampliando as parcerias e permitindo o desenvolvimento de experiências de trabalho coletivo na comunidade e o desenvolvimento de práticas sustentáveis.

A experiência de gestão coletiva, planejamento, contato com a sociedade consumidora de seus produtos e a visibilidade das ações e projetos desenvolvidos no assentamento Colônia I são fatores que se agregam ao amadurecimento de seus moradores na implementação de parcerias e na diversificação de suas atividades produtivas e geradoras de sustentabilidade.

Por meio das entrevistas com alguns moradores do Colônia II, percebe-se que eles valorizam o processo vivido pelos assentados do Colônia I, e reconhecem a importância das parcerias e articulações já desenvolvidas, esse entendimento reforça o interesse de estabelecer parceria com essa comunidade, na implementação das atividades turísticas.

Em relação à percepção dos entrevistados quanto aos conceitos e formulações referentes o turismo e ao Ecoturismo, as impressões estão ligadas ao lazer, ou associadas aos aspectos referentes à natureza. Há que se considerar que as perguntas também não foram direcionadas ou aprofundadas para uma abordagem mais ampla que a atividade ecoturística prescinde, como a participação dos atores envolvidos, gestão, controle, e a geração de benefícios socioambientais. Nesse sentido, a implementação de parcerias e de projetos sustentáveis, requer fundamentalmente o aprofundamento dos aspectos conceituais e metodológicos referentes às ações que serão planejadas.

Quando perguntados se gostariam de ter turistas visitando a comunidade ou a região, 100\% responderam que sim. Para a maioria, o turismo traria renda, mais lazer, mais união, fortaleceria a produção e possibilitaria a troca de conhecimentos. Essa posição fica clara no depoimento de um dos assentados: "já temos visitas de alunos da UNB e podemos passar muitas coisas que sabemos sobre as plantas do cerrado" .

Referente aos cuidados e preparação da comunidade para o desenvolvimento de atividades turísticas, $100 \%$ dos entrevistados manifestou-se pela necessidade de capacitação e preparação dos assentados para novas atividades, assim como a necessidade de se investir na segurança dos visitantes e dos moradores, a produção e o fornecimento de alimentos saudáveis, e o desenvolvimento de atividades educativas para evitar lixo nos mananciais, nascentes e cachoeiras.

Em relação a esse aspecto, foi mencionada a importância de se trabalhar junto às escolas do povoado de Monte Alto, bem como desenvolver um trabalho junto às 
autoridades locais para a devida destinação do lixo. O fato desse local não contar com a coleta e destinação adequada do lixo, tem provocado o escoamento para os rios e nascentes existentes no assentamento Colônia II e mediações, por meio da enxurrada causada pelas águas das chuvas.

Foi mencionada, por alguns dos entrevistados, a importância e a necessidade de realizar trabalhos educativos, junto aos produtores de hortaliças das áreas limítrofes aos assentamentos, sobretudo, no assentamento Colôna II. Alguns desses agricultores estão situados a montante do assentamento, e fazem o uso da água do córrego olho d'água para a irrigação de seus plantios, o mesmo manancial que forma as cachoeiras, principais atrativos turísticos da região.

Demonstrando a necessidade da comunidade se precaver e tomar alguns cuidados para a recepção de visitantes, um dos entrevistados revela que: "O turismo depende de infraestrutura adequada, de pessoal de apoio como seguranças, guardas e guias, visto que não se pode receber turistas de qualquer jeito" .

Quanto aos aspectos relacionados diretamente aos benefícios socioeconômicos, a totalidade dos entrevistados afirmou que as ações voltadas para o turismo trarão ganhos como a diversificação das atividades, aumento de renda, geração de novos empregos, mais locais para o lazer da comunidade, e melhoria da infra-estrutura básica. Aparece na pesquisa uma associação entre a atividade turística e a produção orgânica.

Em relação às atividades/empregos/serviços provenientes da implementação do Ecoturismo, $72 \%$ dos entrevistados afirmou que atividade geraria emprego referente a gerência e administração. Em relação aos serviços de manutenção e limpeza, 63\% acredita na geração de empregos nas áreas de atendimento ao turista, como cozinheiro(a), e artesão, sendo mencionadas outras atividades que poderão ser desenvolvidas, como a de segurança e de guias.

$\mathrm{Na}$ discussão dos benefícios trazidos pelo turismo, as respostas apontam para os aspectos positivos da atividade, como contribuir com a conservação da natureza, ajudar no processo organizativo dos assentados, aspectos educativos junto aos moradores e visitantes, maior divulgação e conhecimento da produção e do consumo de produtos ecológicos.

Uma parte significativa dos entrevistados afirmou que a atividade poderá contribuir para a permanência dos assentados. Este aspecto levantado pelos entrevistados é um bom argumento para que se possa incrementar as iniciativas de apoio aos projetos sustentáveis, podendo também constituir-se em um forte argumento de discussão junto aos órgãos governamentais, no sentido de sensibilizá-los para a implementação de políticas públicas e programas voltados para a diversificação das atividades socioeconômicas e sustentáveis nos assentamentos rurais.

Quanto aos problemas surgidos com a implementação do turismo, a grande maioria respondeu que poderiam ser evitados. "Se for colocado de forma direcionada junto às escolas, não vejo problema" .

Nesse mesmo item, em outro depoimento, percebe-se a visão estratégica e de planejamento, e a importância de se realizar trabalhos educativos: "Depende do que e 
como você vai tocar o turismo; se for feito de maneira não agressiva não traria problemas, colocando cartazes educativos nas entradas".

Foi levantada a possibilidade de desenvolver campanhas e realizar trabalhos educativos para prevenção do fogo no cerrado. Esse aspecto evidencia o potencial das atividades turísticas em proporcionar a Educação Ambiental aos visitantes, e à população local, divulgando as práticas ecológicas e incrementando as atividades voltadas para a revitalização das áreas degradadas inseridas na APA do Descoberto.

Em menor grau de representação, porém importante para a reflexão da pesquisa e para o planejamento das ações voltadas para o desenvolvimento do Ecoturismo, foram apontados alguns aspectos negativos: barulho (2 entrevistados), problemas com o lixo nos atrativos (3), aumento do valor da terra (2), venda de lotes (2), violência (2), intranqüilidade (2) e problemas de drogas (1).

Quanto aos locais mais visitados pelas pessoas das comunidades, $72 \%$ disseram que as cachoeiras existentes no assentamento Colônia II são os lugares preferenciais para visitas. Na sequência, são apontados como lugares preferidos por 03 entrevistados cada um, os atrativos existentes na Reserva Legal, como os montanhas e morros, as matas ciliares, minas e madeiras, havendo uma citação para a gruta, e áreas de nascentes.

...chamar esses outros companheiros que estão fora, trazer eles todos para cá, para olhar para isso, aqui não tem coisa mais linda que o cerrado. O cerrado te dá uma vontade de viver, você vê aquelas madeiras retorcidas, obra da natureza, você vê madeira que é uma obra de arte, isso dá um ânimo, vontade de reflorestar.. (Teobaldo Rocha, morador do assentamento Colônia I).

Além desses lugares, foram mencionados outros aspectos relevantes que podem potencializar as atividades turísticas, como a existência na região de araras que se reproduzem nas montanhas, de emas, de seriemas e de uma significativa diversidade de pássaros.

Em relação aos produtos que poderão ser oferecidos, 100\% dos entrevistados se referiram ao artesanato, seguido pela oferta de alimentos, como os produtos orgânicos, doces, quitandas, representando $45 \%$ das entrevistas. As manifestações culturais, sobretudo a dança goiana do catira, a religiosa como a folia de reis, representando 35\% dos entrevistados, e houve uma citação referente aos frutos do cerrado e plantas medicinais.

Sobre a participação dos entrevistados na implementação do turismo na comunidade, 10 entrevistados responderam que se estimulariam com a atividade, manifestando apoio e desejo de participação, disponibilizando suas plantações para a visitação, incentivando a divisão do trabalho, participando do processo e fortalecendo o diálogo entre os demais assentados. Um entrevistado residente no assentamento Colônia II preferiu não opinar, visto não estar convencido que a atividade possa ser desenvolvida com "garantia de segurança e organização". Evidentemente a implementação de Ecoturismo de base comunitária não obedece apenas aos fatores internos da co- 
munidade. O sucesso das atividades prescinde da participação de atores externos às comunidades, e o estabelecimento de políticas públicas no âmbito das administrações nas esferas, federal, regional e local, incentivadoras desses processos.

Outro aspecto levantado no roteiro foi referente à percepção dos entrevistados sobre quem deveria fazer o planejamento do turismo. A unanimidade (11 entrevistados) acredita que o mesmo deveria ser feito pela associação. Além disso, 10 opinaram que o planejamento deveria ser feito pelos moradores e 08 que o mesmo deveria contar com o apoio de pessoas de fora.

Para o Ecoturismo de base comunitária, a participação dos moradores locais é premissa para assegurar a legitimidade, e representatividade e o sucesso nas ações do projeto. Por sua vez o estabelecimento de parcerias é um instrumento capaz de viabilizar ações (MITRAUD, 2003:382).

Quanto aos atrativos naturais que poderiam ser mais trabalhados nas atividades turísticas, foram citados, por ordem: as cachoeiras (9 entrevistados); trilhas (8); mirantes nos morros (6); e floresta (6). Foi mencionada a horta orgânica como local a ser visitado, e sugeridas algumas modalidades de turismo de aventura, como o rapel e a tirolesa, bem como foi levantado a possibilidade de incluir a cavalgada e o passeios conduzidos por carroças.

Em relação aos tipos de apoio demandados aos moradores para desenvolver as atividades turísticas, 100\% afirmou a necessidade de capacitação, de apoio com recursos financeiros e de melhorias de infra-estrutura, como estradas, transporte, energia elétrica, e infraestrutura com banheiros. Foi explicitada a necessidade de apoio para viabilizar a visita de uma comissão de residentes das comunidades a locais que já desenvolvem atividades ecoturísticas. Outro aspecto mencionado diz respeito, ao estabelecimento de parcerias entre os assentados e instituições com experiências na execução de propostas sustentáveis com vistas a subsidiar as discussões e o planejamento e elaboração de projetos turísticos a ser implementados pelos assentados.

Outros aspectos levantados dizem respeito aos comportamentos sociais, como disciplina, a união, o controle dos recursos e a proteção das belezas naturais, o fortalecimento e o reconhecimento da legitimidade dos processos históricos vividos pelos assentados, a ampliação de sua representação política, e a geração de benefícios socioambientais próprios e para a sociedade em geral.

\section{Considerações finais}

Os processos organizativos dos assentados estão contribuindo para o fortalecimento do capital social local, que se configura pelo fortalecimento dos canais de diálogos com as instituições de apoio e atores locais, que certamente irão fortalecer as políticas e projetos voltados para a implementação de atividades turísticas sustentáveis.

Obviamente, para se colocar em prática as ações apontadas pela pesquisa, fazse necessário, num primeiro momento, a definição de agendas participativas que con- 
templem o envolvimento dos atores internos e externos, e a identificação dos parceiros das esferas regional e federal, no processo de planejamento, elaboração, execução, e avaliação dos projetos que possam ser implementados pelas comunidades.

É visível a percepção dos entrevistados que, se bem planejadas, as atividades turísticas constituirão em ferramentas a serem utilizadas na organização da comunidade, fortalecendo laços familiares e resgatando para dentro do assentamento os trabalhadores que necessitavam sair para trabalhar fora de sua parcela de terra.

Portanto, em diferentes momentos da pesquisa, a perspectiva apresentada pelos assentados ultrapassa a mera visão limitada dos benefícios econômicos a serem gerados pela atividade, não só refletidos sob a ótica da diversificação das atividades, ou da geração de emprego e renda. Nota-se uma percepção clara refletida sob a necessidade de implementar processos que dão uma maior amplitude e visibilidade de atuação das organizações representativas dos assentados. Nessa perspectiva há um visível crescimento e amadurecimento da atuação da Associação dos Produtores do projeto de Colônia I - APPC, que a partir do final de 2002, reformula sua base de atuação e ampliou o leque de representatividade dos seus associados, assegurando o direito ao voto e o de ser votado das mulheres e dos jovens.

Notadamente esse amadurecimento permeia também as parcerias realizadas com as instituições de apoio e de assessoria técnica aos projetos concebidos sob os princípios da sustentabilidade. As indicações da pesquisa são favoráveis ao incremento dos processos organizativos.

O interessante nessa constatação é a percepção das comunidades a respeito de suas potencialidades e visibilidade de sua representação política no âmbito local. Sobretudo quando as manifestações e as ações praticadas evidenciam a solidariedade mútua, e apontam para a realização de ações e iniciativas comunitárias que não se restringem às cercas internas ou limites geográficos dos assentamentos.

A necessidade de trabalhos de Educação Ambiental junto a população local, são reforçados mediante a argumentação dos assentados, sobretudo junto aos proprietários que estão nas áreas limítrofes ao assentamento, por meio de trabalhos de conscientização.

É muito importante o fortalecimento do diálogo e a predisposição demonstrada entre os assentados em torno de um projeto de Ecoturismo. No entanto, esse desafio nos remete à reflexão sobre a relevância dessa discussão junto à esfera de administração pública municipal e aos movimentos sociais, e organizações setoriais existentes no município e cidades próximas, sobretudo, Padre Bernardo e Brazlândia.

Como já mencionado pela sua história e experiência na implementação dos projetos coletivos e participativos a organização do Grupo Vida e Preservação se apresenta como a catalisadora do fortalecimento institucional dos assentados, constituindo se em um aspecto representativo desse processo, principalmente no se refere às atividades sócio-educativas-econômicas desenvolvidas, assim como pela sua experiência no estabelecimento de parcerias do diálogo junto a outras instituições na esfera federal.

Portanto sob o aspecto da percepção político-organizativa dos assentados levantada nesse trabalho, os desafios prementes às atividades voltadas para o Ecoturismo perpassam não 
somente a organização interna dos assentados, mas prescinde da participação de outros atores locais, da capacidade de dar visibilidade a sociedade quanto as suas potencialidades organizativa e de representação política/institucional.

A Importância do processo organizativo no meio rural, associada à realidade dos assentados nos projetos de assentamentos estudados, que configuram o diálogo com diferentes setores da sociedade, são importantes para evidenciar o potencial dessas comunidades frente aos desafios quanto aos recursos naturais e adversidades encontradas pelos mesmos, na implementação de suas atividades produtivas.

Por mais que as condições naturais (solo, relevo, clima), sejam importantes na determinação do desempenho dos assentamentos não são poucos os casos em que os limites físicos foram vencidos pela capacidade organizativa, ou seja, pela construção de uma rede de relações que ampliou as possibilidades de valorização do trabalho dos trabalhadores rurais residentes nos assentamentos (ABRAMOVAY, 1992:306).

A implementação do Ecoturismo de base comunitária concebida sob ótica do planejamento participativo e de processos desenvolvidos sob as premissas da cooperação e da construção coletiva, constituem-se em importantes ferramentas capazes de influenciar nas dinâmicas das políticas públicas, convencionalmente adotados no meio rural, diferentemente daquelas clientelista e assistencialista, e inibidoras da intervenção cidadã dos produtores familiares.

No entanto, o êxito dos empreendimentos e dos projetos sustentáveis a serem desenvolvidos perpassa o reconhecimento por parte dos assentados de sua importância histórica para a região e para a sociedade, e os mesmos se estabeleçam estrategicamente enquanto capital social visto pelo viés dos avanços conquistados historicamente pelos movimentos sociais, e configura um conjunto de características da organização social, como confiança, normas e sistemas, que contribuam para aumentar a eficiência da sociedade, facilitando as ações coordenadas (PUTNAM, 1996).

Outro aspecto de muita importância no fortalecimento das cooperações e dos arranjos locais, refere-se ao cumprimento do papel do Estado junto às comunidades rurais, no sentido que de fato sejam realizadas as prerrogativas inerentes à cidadania das famílias assentadas, como o direito à saúde, educação e informação, garantindo aos mesmos os bens básicos de consumo, como água potável, energia elétrica, transporte e lazer.

O Ecoturismo embora seja analisado e concebido pela ótica da sustentabilidade, ou do turismo responsável, também ocasiona impactos socioambientais, e por isso, sua execução, prescinde da adoção de algumas premissas básicas, sobretudo, referente ao planejamento, à participação, à organização, e à capacitação dos atores envolvidos, ao respeito às diversidades culturais, e à repartição dos benefícios gerados pela atividade.

Asseguradas aos assentados essas prerrogativas, os mesmos poderão ser reconhecidos e valorizados por meio de seus projetos sustentáveis. E nessa perspectiva poderão fomentar a discussão junto às populações locais, e a sociedade em geral, em 
relação aos serviços ambientais prestados a todos por meio da realização de atividades sustentáveis, concebidas e desenvolvidas segundo as premissas da produção de alimentos saudáveis e não poluidora do meio ambiente, pela recuperação e conservação de biodiversidade, dos recursos hídricos e de inclusão social.

Por se tratar de uma proposta ou projeto a ser concebido no espectro do desenvolvimento local sustentável, é imprescindível buscar a eficiência do diálogo entre todos os atores envolvidos.

Os conflitos de interesse resultante do envolvimento de um grande número de atores sociais, portadores de representações e interesses diferenciados, poderiam ser, em princípio, negociados de forma eficiente (VIEIRA; WEBER, 2002:29)

Assim como, a perspectiva da gestão dos recursos naturais que se configuram como "patrimônio comum" para os atores participantes do processo, deverá ser compreendida como condição básica de sobrevivência dos mesmos (VIEIRA; WEBER, 2002).

Em uma proposta de Ecoturismo, onde parte significativa dos atrativos naturais está localizada nas áreas coletivas dos assentados, como nas APPs, Reserva Legal e áreas das Associações, a gestão do seu projeto em longo prazo perpassa necessariamente a adoção de princípios de sustentabilidade, sob o enfoque da atuação solidária entre os atores envolvidos, associada ao estabelecimento de instrumentos educativos, de controle, regulamentação, fiscalização, proteção e conservação dos recursos naturais, sendo esses instrumentos claros e factíveis de serem executados por todos os beneficiários do mesmo.

No entanto, fugindo de uma visão imediatista, o Ecoturismo deve ser concebido a partir de sua importância estratégica no planejamento regional ou global, sem desprezar a necessidade premente de instrumentos e do incremento das políticas públicas já em andamento sendo agregadas ao planejamento participativo das atividades ecoturísticas, espera-se que a partir do estudo ora apresentado, o segundo passo será efetuar um levantamento de problemas que podem dificultar a gestão do Ecoturismo, com o diagnóstico (forças, fraquezas, oportunidades e ameaças) da região a ser trabalhada, os diversos atores da sociedade poderão maximizar as oportunidades e aliar novas propostas segundo as premissas do Ecoturismo participativo de base comunitária viabilizando-o junto aos dois assentamentos pesquisados, a partir das potencialidades gerando novas oportunidades aliadas às atividade socioeconômicas já desenvolvidas.

Segundo Elizabeth Boo, "as ameaças são a degradação do meio ambiente, as injustiças e instabilidades econômicas, e as mudanças socioculturais negativas" e para a mesma, no que tange às oportunidades, será a de geração de renda a partir da integração e da diversificação das atividades, por meio da geração de emprego e renda para comunidades envolvidas, o enraizamento da educação ambiental, e o despertar para a consciência socioambientalista entre visitantes e comunidades (BOO, 1999). 
Rodrigues, J.M.

\section{Referências Bibliográficas}

ABRAMOVAY, R. Paradigma do capitalismo Agrário em Questão. São Paulo: Hucitec, 1992.

BOO, E.. O Planejamento Ecoturístico para Áreas Protegidas. In: LINDBERG, K.; HAWKINS, D. E. (Orgs.). Ecoturismo: um Guia para Planejamento e Gestão. São Paulo: Editora SENAC. São Paulo. 1999

EMBRATUR. Diretrizes para uma Política Nacional de Ecoturismo. Brasília, 1994.

FERNANDES, B.M. Brava Gente: a trajetória do MST e a luta pela terra no Brasil. São Paulo: Ed; Fundação Perseu Abramo, 1999.

MARTINS, L.C.; MELLO, M.I.S. Educação, Meio Ambiente e Desenvolvimento: Programa Interdicisplinar. Brasília: UNB, 1993.

MORAES, W.V. Ecoturismo: um bom negócio com a natureza. Viçosa: UFV, 2000.

MOREIRA, R.J. A pequena produção e a composição orgânica do capital. Revista de Economia Política, v.1/3, julho/setembro 1981: pp.41-55.

OLLAGNON, H.,. Une approche patrimoniale de la qualité du milieu naturel. In: MATHIEU N.; JOLLIVET M. (eds). Du rural à l'environnement, la question de la Nature aujourd'hui. Paris: L'Harmattan, 1989, pp. 258-268

OLIVEIRA, A.U. A geografia das lutas no campo. 2. ed. São Paulo: Contexto, 1989.

PUTNAM, R.D. Comunidade e Democracia: A experiência da Itália Moderna.Rio de Janeiro: Editora Fund. Getúlio Vargas, 1996.

MITRAUD, S. (org). Manual de Ecoturismo de base Comunitária: ferramentas para um planejamento responsável. Brasília: WWF-Brasil, 2003

VASCONCELLOS, M. D. Pierre Bourdieu: a herança sociológica. Educação \& Sociedade, v. 78, 2002, pp. 77-87.

VIEIRA, P.F.; WEBER, J. Gestão de Recursos Naturais Renováveis e Desenvolvimento: Novos desafios para a pesquisa ambiental. São Paulo: CORTEZ, 3. ed. 2002. 


\section{NOTAS}

${ }^{1}$ Relembrando um pensamento da época mencionado por Francisco de Julião: "luta pela reforma agrária é a maior questão de todos os séculos e de todos os povos".

${ }^{2}$ O movimento dos Agricultores Sem Terra- MASTER, teve o apoio do então governador do Estado, Leonel Brizola, "que colocou a Brigada Militar para proteger e ajudar os camponeses", (VASCONCELOS, 2002:27).

${ }^{3}$ Revolução verde, processo mundial, caracterizado principalmente pela "adequação" da agricultura ao modelo industrial, tornando-a empresarial, mecanizada e dependente dos insumos ou "pacotes" agrícolas.

${ }^{4}$ O MST tem suas bases organizativas, o apoio dos sindicatos dos trabalhadores rurais da Comissão Pastoral da Terra- CPT, da Confederação dos Trabalhadores na Agricultura e partidos políticos de esquerda, PT, PDT, PSB, PCB e PC do B.

${ }^{5}$ Segundo o bispo dom Tomás Balduíno, presidente da CPT, há no país cerca de 130 mil trabalhadores acampados e falando sobre as pressões sobre "os que já estão assentados": " Há 67 assentamentos que vivem 11.321 famílias, ameaçadas de despejo".

${ }^{6}$ O Brasil é o segundo maior do mundo em concentração fundiária, perdendo apenas para o Paraguai.

${ }^{7}$ Instituto Nacional de Colonização e Reforma Agrária e Programa Nacional de Educação na Reforma Agrária.

${ }^{8}$ A APA do Descoberto foi criada por meio do Decreto $n^{\circ} 88.940 / 83$, abrange parte do DF e do Município de Padre Bernardo, tem como objetivo principal "proporcionar o bem estar futuro das populações do Distrito Federal e parte do Estado de Goiás,bem como assegurar condições ecológicas satisfatória à represa do mesmo nome".

${ }^{9}$ Segundo algumas estimativas relatadas nos documentos pesquisados, cerca de $70 \%$ da área está alterada.

${ }^{10} \mathrm{O}$ curso tem como finalidade capacitar os assentados segundo as premissas fundamentais do desenvolvimento sustentável, produção associada à conservação da biodiversidade, distribuição justa de renda e benefícios gerados, segurança alimentar e planejamento participativo.

${ }^{11} \mathrm{O}$ uso de práticas conservacionistas para a produção de alimentos, requer a adoção de insumos naturais, como adubos orgânicos, controle de pragas e doenças, e a adoção de medidas de prevenção e de proteção do solo, à vegetação e aos recursos hídricos.

${ }^{12}$ Biofertilizantes são efluentes produzidos por meio da mistura de leite, açúcar e esterco animal, que após um tempo de maturação é diluído em água, útilizado na adubação (rico em nitrogênio) e no controle de pragas e doenças das plantas. 
${ }^{13}$ Foram consultados os projetos desenvolvidos pela APPC, em parcerias com outras instituições, tais como o Educando para a Sustentabilidade,coordenado pelo GTRA/UNB, com o apoio financeiro da Petrobrás/Universidade Solidária; Projeto Conservação e Manejo Sustentável do Bioma Cerrado no Assentamento apoiado pelo CMBBC-Embrapa Cerrados/GTRAUNB, e os relatórios feitos pelos alunos que participam do GTRA/UNB em apoio, assessoria ao PA Colônia I.

${ }^{14}$ A APPC e GTRA e Faculdade de Educação da UNB está discutindo um projeto de criação de uma Escola Familiar Rural em Padre Bernardo.

${ }^{15} \mathrm{Na}$ data da entrevista o valor do salário mínimo era de $\mathrm{R} \$ 240,00$

${ }^{16}$ Afirmação do senhor José Vitorino Barros, residente no assentamento Colônia I.

${ }^{17}$ Depoimento feito por Amival Barbosa da Costa, reside no PA Colônia II.

${ }^{18}$ Segundo uma moradora do PA Colônia I, dona Maria Terezinha da Silva as mulheres fizeram cursos para a produção artesanal utilizando cabaças, confecção de forros de mesa, tapete de linha, e reciclagem de materiais.

${ }^{19}$ Para dona Odália Cardoso dos Santos- presidente da Associação dos Assentados do Colônia II, "se há trabalho, há mais organização ".

${ }^{20}$ Para José Vitorino Barros, morador do assentamento Colônia I, "os maiores benefícios seria a educação e a fixação dos filhos na terra".

${ }^{21}$ Fala do presidente da APPC- João Batista Alves Ribeiro.

${ }^{22}$ Palavras do produtor ecológico do assentamento Colônia II- Crismarino Eleutério.

${ }^{23}$ As cachoeiras de maior potencial para o Ecoturismo, estão no córrego olho d'água -bacia do Rio Verde, na área coletiva dos assentados do PA Colônia II, de aproximadamente 24 ha.

${ }^{24}$ A gruta segundo uma moradora do assentamento Colônia II fica uma hora partindo das cachoeiras descendo o córrego olho d'água.

${ }^{25}$ As mulheres são as responsáveis pela produção de artesanatos e esperam incrementar a produção de alimentos com a construção do espaço multiuso comunitário, que está sendo construído com o apoio do projeto CMBBC.

${ }^{26}$ Segundo um entrevistado e morador do assentamento Colônia I, existe nesse local uma diversidade de frutos do cerrado como araticum, pequi, cajuzinho do cerrado, mangaba, jatobá, mama cadela, carriola, bacupari, e uma variedade de plantas medicinais- como pé de perdiz, guaraná.

${ }^{27}$ Estando inseridos nesse o espectro, as organizações de trabalhadores e proprietários familiares, de artesãos, de moradores urbanos das proximidades, do comércio, associações de guias turísticos e de empreendedores. 
28 Segundo (OLLAGNON,1989), referente a representação dos recursos transapropriativos mediante a categoria de "patrimônio comum", a ser gerido em bases contratuais.

Juarez Martins Rodrigues: Centro Federal de Educação Tecnológica de Rio Verde Instituto Federal Goiano - Campus de Rio Verde

Email: juarez.marodrigues@hotmail.com

Link para o currículo Lattes: http://lattes.cnpq.br/7170696569730662

Data de submissão: 04 de março de 2009

Data do aceite: 17 de abril de 2009 